\title{
Using fuzzy logic to improve the project time and cost estimation based on Project Evaluation and Review Technique (PERT)
}

\author{
Farhad Habibi $^{{ }^{*}}$, Omid Taghipour Birgani ${ }^{b}$, Henk Koppelaar ${ }^{\mathfrak{c}}$ and Stojan Radenovićd $^{d}$
}

\author{
${ }^{a}$ Department of Industrial Engineering, Iran University of Science and Technology, Tehran, Iran \\ ${ }^{b}$ School of Mathematics, Iran University of Science and Technology, Tehran, Iran \\ ${ }^{c}$ Faculty of Electrical Engineering, Mathematics and Computer Science, Delft University of Technology, Netherlands \\ ${ }^{d}$ Faculty of Mechanical Engineering, University of Belgrade, Serbia
}

\section{H R O N I C L E}

Article history:

Received: January 102018

Received in revised format: April

12018

Accepted: April 32018

Available online:

April 42018

Keywords:

Project management

Time estimation

Cost estimation

PERT

Fuzzy logic

Trapezoidal fuzzy numbers

\section{A B S T R A C T}

\begin{abstract}
Among different factors, correct scheduling is one of the vital elements for project management success. There are several ways to schedule projects including the Critical Path Method (CPM) and Program Evaluation and Review Technique (PERT). Due to problems in estimating durations of activities, these methods cannot accurately and completely model actual projects. The use of fuzzy theory is a basic way to improve scheduling and deal with such problems. Fuzzy theory approximates project scheduling models to reality by taking into account uncertainties in decision parameters and expert experience and mental models. This paper provides a step-bystep approach for accurate estimation of time and cost of projects using the Project Evaluation and Review Technique (PERT) and expert views as fuzzy numbers. The proposed method included several steps. In the first step, the necessary information for project time and cost is estimated using the Critical Path Method (CPM) and the Project Evaluation and Review Technique (PERT). The second step considers the duration and cost of the project activities as the trapezoidal fuzzy numbers, and then, the time and cost of the project are recalculated. The duration and cost of activities are estimated using the questionnaires as well as weighing the expert opinions, averaging and defuzzification based on a step-by-step algorithm. The calculating procedures for evaluating these methods are applied in a real project; and the obtained results are explained.
\end{abstract}

\section{Introduction}

Project scheduling and cost planning are key elements of project management. In other words, the success of project management requires achieving an appropriate plan for scheduling and cost of a project. Therefore, appropriate methods should be taken into account for scheduling and estimating project implementation costs. Various methods such as resource leveling and allocation, Gantt chart, network analysis methods, mathematical methods (recently reviewed by Habibi et al. (2018)) and simulation have been put to use for solving project scheduling problems. For example, network methods are efficient tools for solving complex project scheduling problems. In addition to graphical benefits,

* Corresponding author.

E-mail address: farhadhabibi1993@gmail.com (F. Habibi) 
these methods simplify computational costs. Critical Path Method (CPM) and Project Evaluation and Review Technique (PERT) are common examples of network scheduling methods (Bhosale et al., 2017). These two methods aim to assist project managers in monitoring the progress of all project stages (Chitra \& Halder, 2017). The CPM considers all project parameters, such as durations of activities, as crisp values. Given the changing environmental conditions, it is not fully possible to predict future phenomena.

Zareei (2018) applied the CPM for analysis of scheduling and planning the construction of biogas plants. Dolabi et al. (2014) used the CPM to reach a reliable schedule for projects and came to the conclusion that however the CPM can partially reduce uncertainties for scheduling of projects, but a slight change in any activity can lead to infeasibility of the scheduled time. Therefore, the assumption of crisp durations of activities is unfeasible in real projects and this method includes considerable errors to calculations and results. Methods based on statistics and probabilities such as PERT have been created to solve CPM problems and consider the effect of uncertainty on results. In the PERT, the durations of activities are assumed to be stochastic with a certain behavior. In other words, the duration of each activity has a mean and standard deviation that covers the uncertainty. Also, the PERT networks are applied to optimize the time. In PERT networks, time minimization aims to reduce the total completion time of project, if necessary, by allocating additional funds to some activities.

PERT network optimization has been investigated by some researchers. Chanas and Kamburowski (1981) sought to improve and upgrade estimating time parameters of activities in PERT networks, so that the improvement was accurate over existing rules and procedures. Despite the fact that a number of researchers have criticized time distribution in PERT networks, this method is used as an effective tool for stochastic scheduling projects. Azaron et al. (2005) developed a multi-objective model to consider the tradeoff between time and cost in PERT networks. In their model, the generalized Erlang distribution was used to estimate the durations of activities; and a genetic algorithm was applied for solving the proposed model.

In addition to the exposure to uncertainties in some circumstances, the necessary information for projects may not enter organizations at specified and predetermined times and thus they dynamically and probably enter over time leading to more complexity of project planning. This requires taking into account the additional assumptions that result in different outcomes by using different methods. In these types of problems, in addition to the probabilistic duration of activities, the entry of projects is also probabilistic. For analyzing this type of problems in which projects enter organizations in a dynamic environment, dynamic PERT networks are used.

In this regard, Adler et al. (1995) proposed a process perspective for solving dynamic PERT networks in which completion time of projects is determined using a simulation technique. In this perspective, the organization is considered as a probabilistic processing network that has some workstations. Projects continually enter the organization; and the workstations are also serving projects in predetermined orders. Therefore, the organization is faced with a queuing network where projects refer to workstations to get service. In this process perspective, projects are not individually considered with their own resources, but as an integrated system with shared resources available to all projects. In this type of system, projects are completed and ready to be delivered to their owners after passing workstations based on their prerequisite networks, so that the completion time of a project is equivalent to the longest route of the queuing network.

Given some limitations in organizations, Anavi-Isakow and Golany (2003) studied dynamic PERT networks considering the limited capacity in project acceptance and determined the project completion time using the simulation technique. In their research, the resource allocation in dynamic PERT networks with limited capacity was also studied using Cross Entropy (CE) approach which is a simulationbased method. 
The common method of analyzing projects, classical PERT, has numerous problems such as the beta distribution and stochastic variables as well as the estimation of parameters (expected duration and variance). This has led researchers to seek new solutions, e.g. to integrate fuzzy sets with PERT and created a new approach, namely Fuzzy PERT or FPERT.

Since 1965, when fuzzy theory was introduced, it has been applied in various fields. This approach is used to cover the weaknesses in stochastic methods as an appropriate tool. The FPERT was first introduced by Chanas and Kamburowski (1981) to express the durations of activities as fuzzy values. In their proposed method, fuzzy duration of activities was calculated based on three estimates, and an $\alpha-$ cut was utilized to determine the upper and lower bounds for project completion time. According to one of the problems with their method, different $\alpha$ values produced different bounds for project completion time, and thus there were not any effective way to show the activities of critical path in networks.

Mon et al. (1995) sought to solve this problem assuming that the duration of each activity was a positive fuzzy number. Using $\alpha$-cut, they defined an interval for each activity duration. They also used the classical PERT to calculate the duration of each activity and determine the critical path. In other words, they used the linear combination of activity durations to calculate the critical path, but different $\alpha$ values also lead to multiple critical activities and paths. Chanas and Zieliński (2001) assumed that the processing time of each activity could be a certain value, an interval, or a fuzzy number.

In these studies, the uncertainty partially reduced due to utilizing the FPERT and expressing the durations of activities as fuzzy numbers. However, the method of calculating the criticality degree for each activity and path was very complex; hence, the use of some approaches such as the utilizing expert judgment and Fuzzy Delphi Method (FDM) could be very effective in this regard. On the other hand, the mental judgment or prediction based on experts' opinions about the processing time and cost of activities and the use of fuzzy sets for expressing these parameters could reduce the uncertainty by a large extent (Zadeh, 2005). Shipley et al. (1997) used the Fuzzy Delphi Method (FDM) to estimate the durations of activities depending on experts' opinions and without considering weights. In other words, the credibility of the project manager to experts' opinions (the weight and validity of each expert's opinion) was not included in calculations. Kaufmann and Gupta (2003) considered optimistic, most likely and pessimistic views on each activity. This method is the simplified version of beta distribution and still has the problems of PERT.

Chen and Huang (2007) developed the method proposed by Chanas and Kamburowski (1981) by adding new assumptions and trying to calculate the critical degree of activities by taking into account the fuzzy durations for activities and critical indices for all paths in a project. However, it was very difficult to calculate the membership degree of activities, and thus many uncertainties remained unresolved. Mazlum and Güneri (2015) analyzed the obtained results by study on the classical PERT and CPM and fuzzy approach and through combining these methods to improve scheduling. They concluded that there was not any significant difference between results of different methods for scheduling. When the size of projects become larger, these methods were not well-responsive due to existing uncertainties, and thus it was suggested that the project time and cost estimation should be improved by use of innovative combination of methods.

Like the PERT, probabilistic methods cause problems. These methods consider the duration of activities as a probabilistic distribution function e.g. a beta distribution. In this situation, the assumption of estimating the durations by beta distribution function as well as how to estimate the parameters of distribution is not acceptable in many cases. However, attempts have been made to solve these problems using triangular, exponential, and normal distributions, etc., but reasons for the failure of many probabilistic methods are generally as follows: 
- Determining the probabilistic values, probabilistic distribution, mean, and variance of distributions, etc. depends on the repeatability of activities and the statistical inference which is not possible due to the uniqueness principle of the projects. In addition, sometimes the repetition of experiment will not be cost-effective to achieve these values.

- In these models, the expert's inferential deduction from duration of activities is not properly and directly taken into account.

- Time and cost estimations of projects are often very complicated due to assuming various statistical distributions. Also, in many cases, when the duration of activities is considered as a stochastic variable, we cannot obtain a definite probabilistic distribution function for the completion time of project (the sum of several stochastic variables).

This incorrect scheduling can considerably increase the project costs. However, the project cost and scheduling should be evaluated more accurately and the obtained results become closer to the reality by the help of fuzzy sets and involving the experts' opinions and experience. The present research was conducted with the aim to use a PERT-based fuzzy approach in scheduling sections in order to achieve a relative improvement for traditional estimation of project time and cost, and approximate the estimated results to real values.

The use of a fuzzy sets in the project planning and control will have the following benefits:

- Ease of use and simplicity of calculations

- No need for stochastic samples and statistical calculations

- Expression of time and cost of activities as the linguistic variables such as "about 5 months almost from 3 to 6 days" and "definitely more than 100 hours"

- Direct use of experts' mental inference, experience and opinions in these models

The structure of the paper is organized as follows. The first section provides the introduction, the literature review and the research innovation. The second section presents the proposed method and all steps to its implementation. The third section studies a case study in order to show how to implement the proposed framework and evaluate and compare its performance with other similar methods. Section 4 provides results of the case study, and finally, the fifth section presents conclusions and suggestions for future research.

\section{Methodology}

Assuming the available or calculated CPM network of project, the scheduling timetable or total cost of the project is first calculated as crisp values. Then, the scheduling timetable and cost of the project are recalculated using the Project Evaluation and Review Technique (PERT). The PERT aims to plan for project time and cost, and it is applicable in cases of missing information for estimation. In the CPM, it is assumed that the durations of activities are unchanged or changes are very small and negligible, while the PERT assumes that there are changes in the durations of activities. In other words, the PERT is a statistical solution for activities with an uncertain duration and it estimates the probability of completion of activities. However, the PERT is rarely used in construction projects due to its disadvantages, but it has the potential to solve the problems efficiently through correction and improvement. Using the Fuzzy Delphi Method (FDM) and experts' opinions in the PERT, the present research seeks to reduce effects of existing uncertainties on results to a greater extent and estimates the project time and cost more appropriate than the classic PERT. 
* Step 1: First, scheduling timetable or total cost of the project is calculated using the CPM and PERT. The CPM estimates this values by utilizing the precedence network of the project and forward and backward calculations. The PERT uses three estimates for each activity. According to the optimistic estimate $\left(T_{o}\right)$, everything is going properly (best circumstances), but according to the pessimistic estimate $\left(T_{p}\right)$, everything goes forward adversely (with the delay, lack of resources, deterioration of machinery, or bad weather). The third estimate of the PERT uses the most likely estimate $\left(T_{m}\right)$ which assumes the most probable conditions.

In the next step, we estimate the expected time or cost $\left(T_{e}\right)$ based on the weighted mean of probabilities. In other words, different weights are given to probabilities $T_{o}, T_{m}$ and $T_{p}$, and then their mean is calculated. It is assumed that the estimates of $T_{o}$ and $T_{p}$ are equal in terms of probability of occurrence; and the probability of occurrence for $T_{m}$ is four times higher than $T_{o}$ and $T_{p}$. Therefore, the expected time or cost $\left(T_{e}\right)$ can be calculated using the Eq. (1):

$$
T_{e}=\frac{T_{o}+4 T_{m}+T_{p}}{6}
$$

The standard deviation $\left(S_{t}\right)$ and variance $\left(V_{t}\right)$ of time or cost parameters for each activity can be calculated using the Eq. (2) and Eq. (3):

$$
\begin{aligned}
& S_{t}=\frac{T_{p}-T_{o}}{6} \\
& V_{t}=\left(S_{t}\right)^{2}
\end{aligned}
$$

When values of expected time or cost $\left(T_{e}\right)$, standard deviation $\left(S_{t}\right)$ and variance $\left(V_{t}\right)$ are calculated for each activity, like the CPM, the forward and backward calculations are performed for all activities in the network and then, the total expected time or cost of project $\left(T_{e}\right)$ is calculated. After calculation of $T_{e}$, we can calculate variance $\left(V_{t}\right)$ of the completion time or cost of the project through the critical activities and path.

* Step 2: $N$ experts are selected to estimate the duration or cost of project activities and each of them provide a certain time or cost using verbal variables in the forms of trapezoidal fuzzy numbers according to their knowledge and experience. These opinions are presented in the form of Eq. (4):

$$
\tilde{T}_{i j}^{k}=\left(a_{i j}^{k}, b_{i j}^{k}, c_{i j}^{k}, d_{i j}^{k}\right) \quad \mathrm{i}=1,2, \ldots, \mathrm{N} ; j=1,2, \ldots, \mathrm{L}
$$

In the Equation (4), $i$ is the index of experts $(i=1,2, \ldots, N) . k$ represents the iteration or step number; and $j$ refers to the activity number $(j=1,2, \ldots, L)$. Furthermore, $\tilde{T}_{i j}^{k}$ is the fuzzy duration or cost of activity $j$ at the step $k$ estimated by expert $i$ as a trapezoidal fuzzy number. $a_{i j}^{k}, b_{i j}^{k}, c_{i j}^{k}$ and $d_{i j}^{k}$ are trapezoidal fuzzy numbers which refer to the most optimistic, possible optimistic, possible pessimistic, and the most pessimistic states, respectively.

* Step 3: In this section, the time or cost is proposed by experts for each activity put in a category. In other words, this category (set) for activity $j$ at the step $k$ is defined as the Equation (5):

$$
D_{j}^{k}=\left[\begin{array}{c}
T_{1 j}^{k} \\
T_{2 j}^{k} \\
\vdots \\
T_{N j}^{k}
\end{array}\right] \quad j=1,2, \ldots, L
$$


* Step 4: In this step, weighing and averaging of the experts' opinions set are performed for activity $j$ at the step $k$. The project management team assigns a weight to each expert for each activity. This weight represents the level of management team trust in the experts' comment on activities. This trust in the expert $i$ for duration or cost of activity $j$ is shown by $W_{i j}$. After determining $D_{j}^{k}$ and $W_{i j}$, this step calculates the mean of category for the activity $j$ at the step $k$ according to the Eq. (6):

$$
\bar{T}_{j}^{k}=\left(\bar{a}_{j}^{k}, \bar{b}_{j}^{k}, \bar{c}_{j}^{k}, \bar{d}_{j}^{k}\right)=\left(\frac{\sum_{i=1}^{N} W_{i j} a_{i j}^{k}}{\sum_{i=1}^{N} W_{i j}}, \frac{\sum_{i=1}^{N} W_{i j} b_{i j}^{k}}{\sum_{i=1}^{N} W_{i j}}, \frac{\sum_{i=1}^{N} W_{i j} c_{i j}^{k}}{\sum_{i=1}^{N} W_{i j}}, \frac{\sum_{i=1}^{N} W_{i j} d_{i j}^{k}}{\sum_{i=1}^{N} W_{i j}}\right)
$$

* Step 5: After calculating $\bar{T}_{j}^{k}$, if the process is stable, the algorithm stops; and the obtained $\bar{T}_{j}^{k}$ is defuzzified by Eqs. (7)-(10) and considered as the estimation of duration or cost of activity $j$.

$$
\begin{aligned}
& D T_{j}^{(1)}=\frac{\bar{b}_{j}^{k}+\bar{c}_{j}^{k}}{2} \\
& D T_{j}^{(2)}=\frac{\bar{a}_{j}^{k}+\frac{\bar{b}_{j}^{k}+\bar{c}_{j}^{k}}{2}+\bar{d}_{j}^{k}}{3} \\
& D T_{j}^{(3)}=\frac{\bar{a}_{j}^{k}+\bar{b}_{j}^{k}+\bar{c}_{j}^{k}+\bar{d}_{j}^{k}}{4} \\
& D T_{j}^{(4)}=\frac{\bar{a}_{j}^{k}+2\left(\bar{b}_{j}^{k}+\bar{c}_{j}^{k}\right)+\bar{d}_{j}^{k}}{6}
\end{aligned}
$$

Otherwise, the difference from the average of duration or cost of activities is calculated for each expert according to the Eq. (11):

$$
F_{j}^{k}=\left(\bar{a}_{j}^{k}-a_{i j}^{k}, \bar{b}_{j}^{k}-b_{i j}^{k}, \bar{c}_{j}^{k}-c_{i j}^{k}, \bar{d}_{j}^{k}-d_{i j}^{k}\right) \quad \mathrm{i}=1,2, \ldots, N ; j=1,2, \ldots, L
$$

Then, this information is sent to each expert and the next step begins.

* Step 6: After submitting the information, each expert is asked to provide a new estimate of duration or cost for each activity based on the available information. Then, according to the second step, these new opinions, are presented as trapezoidal fuzzy numbers based on the Eq. (12):

$$
\tilde{T}_{i j}^{k+1}=\left(a_{i j}^{k+1}, b_{i j}^{k+1}, c_{i j}^{k+1}, d_{i j}^{k+1}\right) \quad \mathrm{i}=1,2, \ldots, \mathrm{N} ; j=1,2, \ldots, \mathrm{L}
$$

As shown, the algorithm enters the next iteration $(k+1)$. Now, according to new experts' opinions, the algorithm returns to the Step 3 and is iterated by replacing $k+1$ with $k$. These iterations continue until the stop condition is met.

\subsection{Stop condition of the algorithm}

As was explained in the Step 5, when $\bar{T}_{j}^{k}$ for all the activity reaches quiescence, the algorithm will stop; and the obtained trapezoidal number is considered as the estimated duration or cost of activity $j$. Two methods are suggested to determine the stability of process as follows: 
- Method 1: A natural number $r$ is defined by the project management team as the maximum number of iteration, and the process becomes stable and the algorithm stops when the number of iterations $(k)$ is equal to $r(k=r)$. This method is very simple, but it may not be very accurate in some cases. Therefore, the use of this method depends on the knowledge of the project management team about activities and experts.

- Method 2: A value of $\varepsilon$ is set by the project management team, and when the difference of each expert opinion $\left(\tilde{T}_{i j}^{k}\right)$ from the mean of category $\left(\bar{T}_{j}^{k}\right)$ reaches lower than $\varepsilon$, the process reaches quiescence. Thus, the Eq. (13) should be true for all categories to stop the algorithm. $\delta\left(\bar{T}_{j}^{k}, \tilde{T}_{i j}^{k}\right) \leq \varepsilon$

As shown, calculations of Method 2 are more complex than those of Method 1, but it seems that the accuracy of calculations is higher in Method 2. In the second method, some experts may have quite different opinions from the others and insist on their opinions in different iterations. In this case, a significant difference between the expert's opinion and the mean of category is made and the process doesn't reach stability. Therefore, in this case, it is suggested that some innovative techniques, such as deleting outlier comments from a desired category, be applied.

In general, steps of Fig. 1 should be taken in estimating the time and cost of the project.

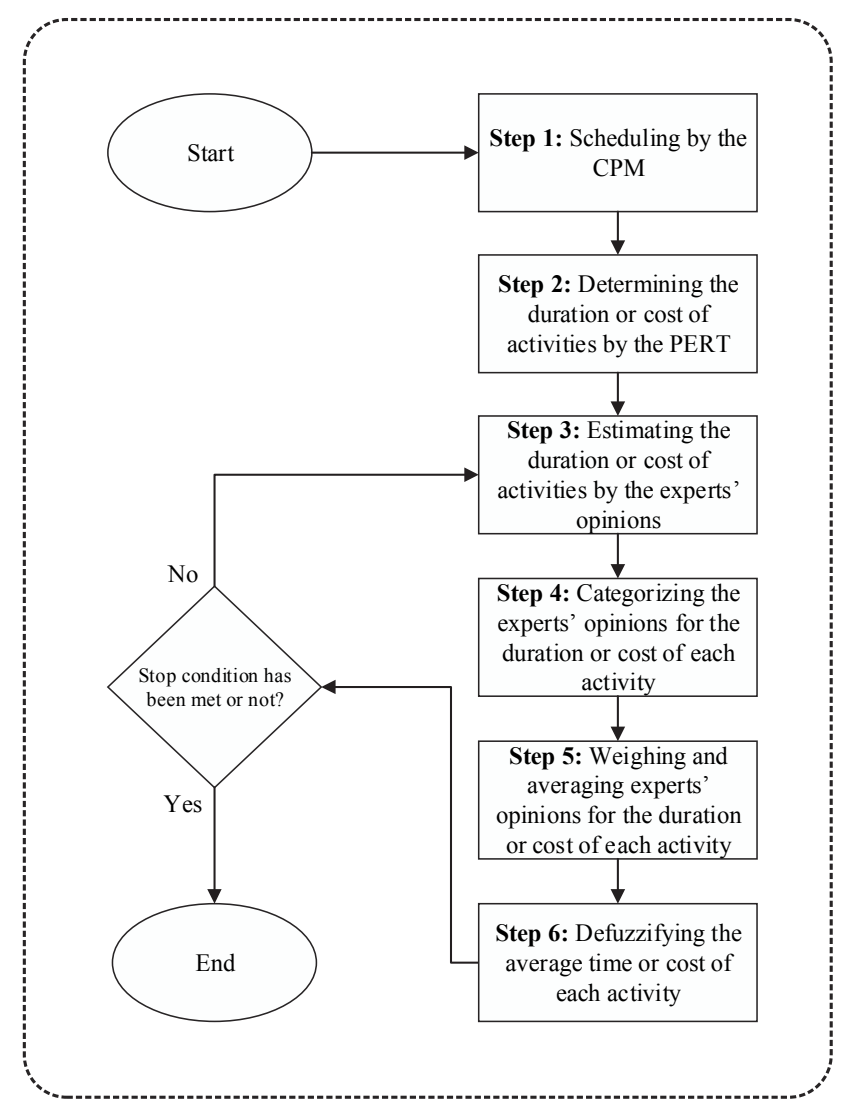

Fig. 1. Flowchart of the proposed method

\section{Case study}

As a case of the proposed method, a construction project for a 5-story building from the start until the end of constructing foundation consisting of 11 activities on an area of 170 square meters in Tehran, 
Iran, is studied. During the implementation process, a survey through questionnaires was performed on three experts $(N=3)$ about the cost and time of each activity. The obtained results were studied and evaluated. Using the proposed method, the project management team studied the duration and cost of activities which are expressed as trapezoidal fuzzy numbers. It was also assumed that Method 1 was used for the stability of process and the stop condition and the algorithm would stop after 3 iterations $(r=3)$. Project activities and their related parameters are presented in Table 1.

Table 1

Project activities

\begin{tabular}{ccccc}
\hline Number & Activity & $\begin{array}{c}\text { Duration } \\
\text { (days) }\end{array}$ & $\begin{array}{c}\text { Cost (million mon- } \\
\text { etary units) }\end{array}$ & Prerequisite \\
\hline 1 & Equipping the workshop & 8 & 2.5 & -- \\
2 & Excavating & 7 & 9.0 & 1 \\
3 & Foundation form setting and grading & 4 & 2.0 & 2 \\
4 & Lean concrete pouring & 2 & 1.0 & 3 \\
5 & Purchasing and preparing the rebar & 8 & 8.0 & 1 \\
6 & Rebar binding & 7 & 3.0 & 4,5 \\
7 & Concrete shuttering & 5 & 1.5 & 6 \\
8 & Designing the column base plates & 2 & 2.0 & 7 \\
9 & Concrete pouring & 2 & 6.5 & 8 \\
10 & Concrete curing & 7 & 0.4 & 9 \\
11 & Concrete de-shuttering & 2 & 0.3 & 10 \\
\hline
\end{tabular}

\subsection{Estimating project time}

First, using the CPM, the project completion time is obtained equal to 46 days, and then, according to Table 2, it is recalculated by the PERT. According to Table 2, the duration of each activity is set in three optimistic, most likely, and optimistic states. Afterwards, the expected time, standard deviation and variance are measured for each activity using the PERT and Eq. (1) to Eq. (3). Finally, the expected project completion time is calculated by summing the total duration of critical activities.

Table 2

Calculation of expected duration, standard deviation and variance using PERT

\begin{tabular}{|c|c|c|c|c|c|c|c|}
\hline \multirow[b]{2}{*}{ Activity } & \multicolumn{3}{|c|}{ Duration (days) } & \multirow{2}{*}{$\begin{array}{c}\text { Expected dura- } \\
\text { tion }\left(\mathrm{T}_{\mathrm{e}}\right)\end{array}$} & \multirow{2}{*}{$\begin{array}{c}\begin{array}{r}\text { Standard } \\
\text { deviation }\end{array} \\
\frac{T_{p}-T_{o}}{6}\end{array}$} & \multirow[b]{2}{*}{ 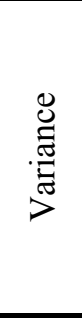 } & \multirow[b]{2}{*}{ : } \\
\hline & 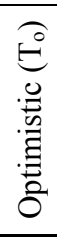 & 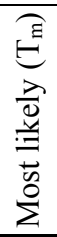 & 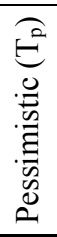 & & & & \\
\hline Equipping the workshop & 6 & 8 & 12 & 8.33 & 1 & 1 & $\checkmark$ \\
\hline Excavating & 6 & 7 & 10 & 7.33 & 0.67 & 0.44 & $\checkmark$ \\
\hline Foundation form setting and grading & 2 & 4 & 6 & 4.00 & 0.67 & 0.44 & $\checkmark$ \\
\hline Lean concrete pouring & 1 & 2 & 3 & 2.00 & 0.33 & 0.11 & $\checkmark$ \\
\hline Purchasing and preparing the rebar & 5 & 8 & 10 & 7.83 & 0.83 & 0.69 & \\
\hline Rebar binding & 5 & 7 & 9 & 7.00 & 0.67 & 0.44 & $\checkmark$ \\
\hline Concrete shuttering & 3 & 5 & 7 & 5.00 & 0.67 & 0.44 & $\checkmark$ \\
\hline Designing the column base plates & 1 & 2 & 4 & 2.17 & 0.50 & 0.25 & $\checkmark$ \\
\hline Concrete pouring & 1 & 2 & 3 & 2.00 & 0.33 & 0.11 & $\checkmark$ \\
\hline Concrete curing & 5 & 7 & 9 & 7.00 & 0.67 & 0.44 & $\checkmark$ \\
\hline Concrete de-shuttering & 1 & 2 & 3 & 2.00 & 0.33 & 0.11 & $\checkmark$ \\
\hline \multicolumn{4}{|c|}{ The sum (for critical activities) } & 46.83 & 1.95 & 3.80 & -- \\
\hline
\end{tabular}


As shown, the project completion time is equal to 46.83 days according to PERT considering the optimistic, most likely and pessimistic states for the durations of activities. The probability of completing project in 49 days is approximately $87 \%$ using the normal distribution table and Eq. (14) and Eq. (15). In the following, estimation is performed according to the proposed framework.

$$
\begin{aligned}
& Z=\frac{T_{S}-T_{E}}{\sigma_{T}} \\
& P(49)=\phi(\mathrm{Z})=\phi\left(\frac{49-46.83}{1.95}\right)=0.8671 .
\end{aligned}
$$

Table 3

\begin{tabular}{|c|c|c|c|c|c|c|c|c|c|c|c|c|c|}
\hline \multirow{3}{*}{ 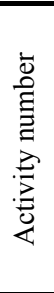 } & \multirow{3}{*}{ 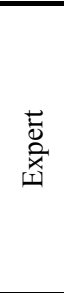 } & \multicolumn{4}{|c|}{ Duration (days) } & \multirow{3}{*}{ 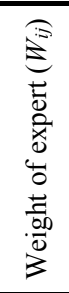 } & \multicolumn{4}{|c|}{ Average duration (days) } & \multirow{3}{*}{$\begin{array}{l}\text { Defuzzifying } \\
\frac{\bar{b}_{j}+\bar{c}_{j}}{2}\end{array}$} & \multirow{3}{*}{ 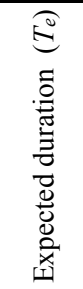 } & \multirow{3}{*}{ 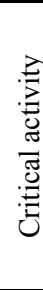 } \\
\hline & & 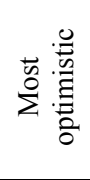 & 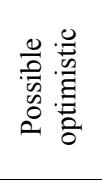 & 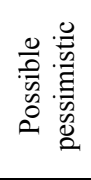 & 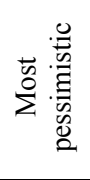 & & 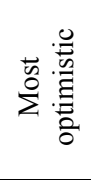 & 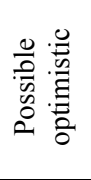 & 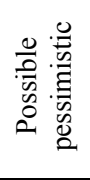 & 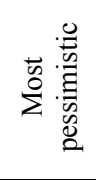 & & & \\
\hline & & $a_{j}$ & $b_{j}$ & $c_{j}$ & $d_{j}$ & & $\bar{a}_{j}$ & $\bar{b}_{j}$ & $\bar{c}_{j}$ & $\bar{d}_{j}$ & & & \\
\hline \multirow{3}{*}{1} & 1 & 6 & 7 & 8 & 10 & 0.2 & \multirow{3}{*}{5.80} & \multirow{3}{*}{7.30} & \multirow{3}{*}{8.80} & \multirow{3}{*}{10.50} & \multirow{3}{*}{8.05} & \multirow{3}{*}{8.33} & \multirow{3}{*}{$\checkmark$} \\
\hline & 2 & 5 & 7 & 9 & 11 & 0.5 & & & & & & & \\
\hline & 3 & 7 & 8 & 9 & 10 & 0.3 & & & & & & & \\
\hline \multirow{3}{*}{2} & 1 & 5 & 6 & 8 & 10 & 0.2 & \multirow{3}{*}{5.50} & \multirow{3}{*}{6.50} & \multirow{3}{*}{7.70} & \multirow{3}{*}{8.90} & \multirow{3}{*}{7.10} & \multirow{3}{*}{7.33} & \multirow{3}{*}{$\checkmark$} \\
\hline & 2 & 6 & 7 & 8 & 9 & 0.5 & & & & & & & \\
\hline & 3 & 5 & 6 & 7 & 8 & 0.3 & & & & & & & \\
\hline & 1 & 1 & 2 & 3 & 4 & 0.2 & & & & & & & \\
\hline 3 & 2 & 2 & 3 & 4 & 5 & 0.5 & 1.50 & 2.50 & 3.50 & 4.50 & 3.00 & 4.00 & $\checkmark$ \\
\hline & 3 & 1 & 2 & 3 & 4 & 0.3 & & & & & & & \\
\hline & 1 & 1 & 2 & 2 & 3 & 0.2 & & & & & & & \\
\hline 4 & 2 & 2 & 3 & 3 & 3 & 0.5 & 1.50 & 2.20 & 2.50 & 2.70 & 2.35 & 2.00 & $\checkmark$ \\
\hline & 3 & 1 & 1 & 2 & 2 & 0.3 & & & & & & & \\
\hline & 1 & 5 & 7 & 8 & 9 & 0.2 & & & & & & & \\
\hline 5 & 2 & 7 & 8 & 10 & 12 & 0.5 & 6.30 & 7.50 & 9.00 & 10.50 & 8.25 & 7.83 & \\
\hline & 3 & 6 & 7 & 8 & 9 & 0.3 & & & & & & & \\
\hline & 1 & 5 & 6 & 7 & 8 & 0.2 & & & & & & & \\
\hline 6 & 2 & 5 & 7 & 8 & 9 & 0.5 & 4.70 & 6.20 & 7.20 & 8.50 & 6.70 & 7.00 & $\checkmark$ \\
\hline & 3 & 4 & 5 & 6 & 8 & 0.3 & & & & & & & \\
\hline & 1 & 1 & 2 & 2 & 3 & 0.2 & & & & & & & \\
\hline 7 & 2 & 2 & 3 & 3 & 4 & 0.5 & 1.80 & 2.80 & 3.10 & 4.10 & 2.95 & 5.00 & $\checkmark$ \\
\hline & 3 & 2 & 3 & 4 & 5 & 0.3 & & & & & & & \\
\hline & 1 & 1 & 2 & 3 & 3 & 0.2 & & & & & & & \\
\hline 8 & 2 & 2 & 2 & 3 & 3 & 0.5 & 1.50 & 2.00 & 2.70 & 2.70 & 2.35 & 2.17 & $\checkmark$ \\
\hline & 3 & 1 & 2 & 2 & 2 & 0.3 & & & & & & & \\
\hline & 1 & 1 & 2 & 2 & 2 & 0.2 & & & & & & & \\
\hline 9 & 2 & 1 & 1 & 1 & 2 & 0.5 & 1.00 & 1.20 & 1.20 & 2.00 & 1.20 & 2.00 & $\checkmark$ \\
\hline & 3 & 1 & 1 & 1 & 2 & 0.3 & & & & & & & \\
\hline & 1 & 5 & 6 & 7 & 8 & 0.2 & & & & & & & \\
\hline 10 & 2 & 6 & 7 & 7 & 8 & 0.5 & 5.50 & 6.80 & 7.00 & 8.00 & 6.90 & 7.00 & $\checkmark$ \\
\hline & 3 & 5 & 7 & 7 & 8 & 0.3 & & & & & & & \\
\hline & 1 & 1 & 2 & 2 & 3 & 0.2 & & & & & & & \\
\hline 11 & 2 & 1 & 1 & 2 & 2 & 0.5 & 1.00 & 1.50 & 2.00 & 2.50 & 1.75 & 2.00 & $\checkmark$ \\
\hline & 3 & 1 & 2 & 2 & 3 & 0.3 & & & & & & & \\
\hline & & & & Projec & ompl & on tim & (days) & & & & 42.35 & 46.83 & -- \\
\hline
\end{tabular}

Calculation of activities duration using proposed method

Table 3 shows the experts' opinions about durations of activities in the optimistic, most likely and pessimistic states as fuzzy trapezoidal numbers which are obtained using questionnaires. The weights 
of $0.2,0.5$ and 0.3 are given to the experts according to their experience. After that, the mean of each category is calculated according to Eq. (6), and the mean fuzzy number is defuzzified according to the Eq. (7). Finally, the time of critical activities is summed and the project completion time is estimated. For instance, 3 surveys were done on experts for Activity 2 (excavating), and the processing time of this activity was calculated according to the Eq. (16):

$$
\bar{T}_{2}^{3}=\left(\bar{a}_{2}^{3}, \bar{b}_{2}^{3}, \bar{c}_{2}^{3}, \bar{d}_{2}^{3}\right)
$$

According to Eq. (6), we have:

$$
\begin{array}{ll}
\bar{a}_{2}^{3}=\frac{(0.2 * 5)+(0.5 * 6)+(0.3 * 5)}{0.2+0.5+0.3}=5.50 & \bar{b}_{2}^{3}=\frac{(0.2 * 6)+(0.5 * 7)+(0.3 * 6)}{0.2+0.5+0.3}=6.50 \\
\bar{c}_{2}^{3}=\frac{(0.2 * 8)+(0.5 * 8)+(0.3 * 7)}{0.2+0.5+0.3}=7.70 & \bar{d}_{2}^{3}=\frac{(0.2 * 10)+(0.5 * 9)+(0.3 * 8)}{0.2+0.5+0.3}=8.90
\end{array}
$$

According to Eq. (7), for its defuzzification, we have:

$D T_{2}=\frac{\bar{b}_{2}+\bar{c}_{2}}{2}=\frac{6.5+7.7}{2}=7.1$

And the duration of all activities is calculated by this method. According to the Table 3 and defuzzifying the durations of activities, the completion time of this project was equal to 42.35 days.

\subsection{Estimating project cost}

In this section, we replicate the algorithm to calculate the cost of activities in order to estimate the total cost of the project. According to the Table 1 and the CPM, the cost of critical activities of the project was 28.2 million monetary units, and the total cost of the project was 36.2 million monetary units. In the next step, the cost of processing activities is recalculated using the PERT. According to Table 4 and

\begin{tabular}{|c|c|c|c|c|c|c|}
\hline \multirow[b]{2}{*}{ Activity } & \multicolumn{3}{|c|}{$\begin{array}{l}\text { Cost (million } \\
\text { monetary units) }\end{array}$} & \multirow{2}{*}{$\begin{array}{c}\begin{array}{c}\text { Expected cost } \\
\left(\mathrm{C}_{\mathrm{e}}\right)\end{array} \\
\frac{C_{o}+4 C_{m}+C_{p}}{6}\end{array}$} & \multirow{2}{*}{$\begin{array}{l}\begin{array}{l}\text { Standard } \\
\text { deviation }\end{array} \\
\frac{C_{p}-C_{o}}{6}\end{array}$} & \multirow[b]{2}{*}{ 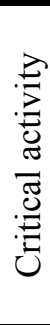 } \\
\hline & 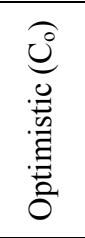 & 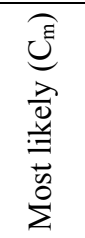 & 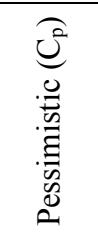 & & & \\
\hline Equipping the workshop & 2.00 & 3.00 & 4.00 & 3.00 & 0.33 & $\sqrt{ }$ \\
\hline Excavating & 6.50 & 8.00 & 12.00 & 8.42 & 0.92 & $\checkmark$ \\
\hline Foundation form setting and grading & 1.00 & 2.00 & 3.00 & 2.00 & 0.33 & $\checkmark$ \\
\hline Lean concrete pouring & 0.50 & 0.80 & 1.00 & 0.78 & 0.08 & $\checkmark$ \\
\hline Purchasing and preparing the rebar & 6.50 & 7.50 & 8.50 & 7.50 & 0.33 & \\
\hline Rebar binding & 2.50 & 3.50 & 4.50 & 3.50 & 0.33 & $\checkmark$ \\
\hline Concrete shuttering & 1.00 & 1.50 & 2.00 & 1.50 & 0.17 & $\checkmark$ \\
\hline Designing the column base plates & 1.00 & 1.50 & 2.50 & 1.58 & 0.25 & $\checkmark$ \\
\hline Concrete pouring & 5.00 & 6.00 & 7.00 & 6.00 & 0.33 & $\checkmark$ \\
\hline Concrete curing & 0.10 & 0.20 & 0.30 & 0.20 & 0.03 & $\checkmark$ \\
\hline Concrete de-shuttering & 0.20 & 0.30 & 0.40 & 0.30 & 0.03 & $\checkmark$ \\
\hline \multicolumn{4}{|c|}{ The sum of cost (for critical activities) } & 27.28 & 2.82 & -- \\
\hline \multicolumn{4}{|c|}{ Total cost (million monetary units) } & 34.78 & 3.15 & -- \\
\hline
\end{tabular}
the PERT, the cost of critical activities of project was 27.28 million monetary units, and the project total cost was 34.78 million monetary units.

Table 4

Calculation of expected cost and standard deviation using PERT 
According to Eq. (17) and Eq. (18), the probability that the total cost of project was 37 million monetary units, was approximately $76 \%$ using the normal distribution table.

$$
\begin{aligned}
& Z=\frac{C_{S}-C_{E}}{\sigma_{C}} \\
& P(49)=\phi(Z)=\phi\left(\frac{37-34.78}{3.15}\right)=0.7595
\end{aligned}
$$

Now, we recalculated the total cost of project using the questionnaire and expert opinions which are expressed as trapezoidal fuzzy numbers. According to Table 5, in the third replication, the cost of critical activities was 23.98 million monetary units and the total cost of the project was 29.88 million monetary units. It should be noted that the calculations were similar to the calculations of estimated time presented in the previous section.

Table 5

\begin{tabular}{|c|c|c|c|c|c|c|c|c|c|c|c|c|c|}
\hline \multirow{3}{*}{ 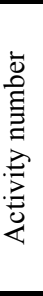 } & \multirow{3}{*}{$\begin{array}{l}\text { 志 } \\
\text { 啇 } \\
\text { In }\end{array}$} & \multicolumn{4}{|c|}{ Cost (million monetary units) } & \multirow{3}{*}{ 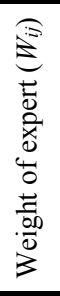 } & \multicolumn{4}{|c|}{ Average cost (million monetary units) } & \multirow{3}{*}{$\begin{array}{l}\text { Defuzzifying } \\
\frac{\bar{b}_{j}+\bar{c}_{j}}{2}\end{array}$} & \multirow{3}{*}{ 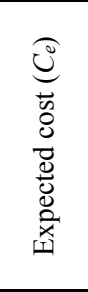 } & \multirow{3}{*}{ : } \\
\hline & & \multirow{2}{*}{ 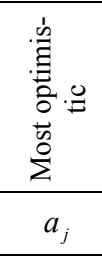 } & \multirow{2}{*}{ 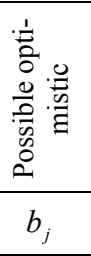 } & \multirow{2}{*}{ 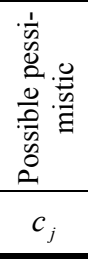 } & \multirow{2}{*}{ 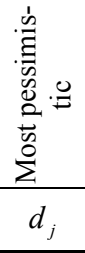 } & & \multirow{2}{*}{ 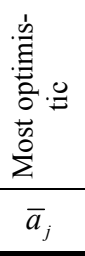 } & \multirow{2}{*}{ 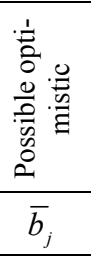 } & \multirow{2}{*}{ 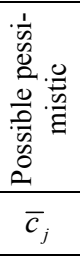 } & \multirow{2}{*}{ 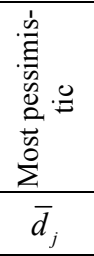 } & & & \\
\hline & & & & & & & & & & & & & \\
\hline \multirow{3}{*}{1} & 1 & 1.0 & 1.3 & 1.6 & 2.0 & 0.2 & \multirow{3}{*}{1.25} & \multirow{3}{*}{1.71} & \multirow{3}{*}{2.17} & \multirow{3}{*}{2.56} & \multirow{3}{*}{1.94} & \multirow{3}{*}{3.00} & \\
\hline & 2 & 1.5 & 2.0 & 2.5 & 3.0 & 0.5 & & & & & & & $\checkmark$ \\
\hline & 3 & 1.0 & 1.5 & 2.0 & 2.2 & 0.3 & & & & & & & \\
\hline & 1 & 5.0 & 7.0 & 8.0 & 12.0 & 0.2 & & & & & & & \\
\hline 2 & 2 & 6.0 & 7.0 & 8.0 & 10.0 & 0.5 & 6.40 & 7.60 & 8.60 & 10.70 & 8.10 & 8.42 & $\checkmark$ \\
\hline & 3 & 8.0 & 9.0 & 10.0 & 11.0 & 0.3 & & & & & & & \\
\hline & 1 & 1.0 & 1.2 & 1.5 & 2.0 & 0.2 & & & & & & & \\
\hline 3 & 2 & 1.0 & 1.5 & 1.5 & 2.0 & 0.5 & 0.85 & 1.29 & 1.50 & 2.00 & 1.40 & 2.00 & $\checkmark$ \\
\hline & 3 & 0.5 & 1.0 & 1.5 & 2.0 & 0.3 & & & & & & & \\
\hline & 1 & 0.5 & 0.8 & 0.9 & 1.0 & 0.2 & & & & & & & \\
\hline 4 & 2 & 0.6 & 0.7 & 0.8 & 1.0 & 0.5 & 0.58 & 0.72 & 0.82 & 0.97 & 0.77 & 0.78 & $\checkmark$ \\
\hline & 3 & 0.6 & 0.7 & 0.8 & 0.9 & 0.3 & & & & & & & \\
\hline & 1 & 5.0 & 5.0 & 6.5 & 7.5 & 0.2 & & & & & & & \\
\hline 5 & 2 & 5.0 & 5.5 & 6.0 & 7.0 & 0.5 & 5.15 & 5.55 & 6.25 & 7.10 & 5.90 & 7.50 & \\
\hline & 3 & 5.5 & 6.0 & 6.5 & 7.0 & 0.3 & & & & & & & \\
\hline & 1 & 2.0 & 3.0 & 3.5 & 4.0 & 0.2 & & & & & & & \\
\hline 6 & 2 & 2.0 & 2.5 & 3.0 & 3.5 & 0.5 & 1.85 & 2.45 & 2.95 & 3.45 & 2.70 & 3.50 & $\checkmark$ \\
\hline & 3 & 1.5 & 2.0 & 2.5 & 3.0 & 0.3 & & & & & & & \\
\hline & 1 & 1.0 & 1.5 & 1.7 & 2.0 & 0.2 & & & & & & & \\
\hline 7 & 2 & 0.7 & 1.0 & 1.3 & 1.8 & 0.5 & 0.79 & 1.10 & 1.38 & 1.81 & 1.24 & 1.50 & $\checkmark$ \\
\hline & 3 & 0.8 & 1.0 & 1.3 & 1.7 & 0.3 & & & & & & & \\
\hline & 1 & 0.7 & 1.0 & 1.3 & 1.5 & 0.2 & & & & & & & \\
\hline 8 & 2 & 1.0 & 1.2 & 1.4 & 1.6 & 0.5 & 0.94 & 1.19 & 1.44 & 1.70 & 1.32 & 1.58 & $\checkmark$ \\
\hline & 3 & 1.0 & 1.3 & 1.6 & 2.0 & 0.3 & & & & & & & \\
\hline & 1 & 5.0 & 5.3 & 5.8 & 6.5 & 0.2 & & & & & & & \\
\hline 9 & 2 & 5.5 & 6.0 & 6.5 & 7.0 & 0.5 & 5.25 & 5.71 & 6.21 & 6.75 & 5.96 & 6.00 & $\checkmark$ \\
\hline & 3 & 5.0 & 5.5 & 6.0 & 6.5 & 0.3 & & & & & & & \\
\hline & 1 & 0.1 & 0.2 & 0.2 & 0.3 & 0.2 & & & & & & & \\
\hline 10 & 2 & 0.1 & 0.2 & 0.3 & 0.4 & 0.5 & 0.13 & 0.23 & 0.28 & 0.38 & 0.26 & 0.20 & $\checkmark$ \\
\hline & 3 & 0.2 & 0.3 & 0.3 & 0.4 & 0.3 & & & & & & & \\
\hline & 1 & 0.2 & 0.3 & 0.4 & 0.4 & 0.2 & & & & & & & \\
\hline 11 & 2 & 0.1 & 0.2 & 0.3 & 0.4 & 0.5 & 0.15 & 0.25 & 0.35 & 0.40 & 0.30 & 0.30 & $\checkmark$ \\
\hline & 3 & 0.2 & 0.3 & 0.4 & 0.4 & 0.3 & & & & & & & \\
\hline & & & & sum o & osts (1 & critic & activit & & & & 23.98 & 27.28 & -- \\
\hline & & & Proj & ct tota & ost (m & on $\mathrm{m}$ & etary u & & & & 29.88 & 34.78 & -- \\
\hline
\end{tabular}

Calculation of activities cost using proposed method 


\section{Computational results}

\subsection{Results of time estimation}

According to the Table 6, the real completion time of the project was 38 days. It was 46 days according to the CPM, and 47 through the PERT. However, it was equal to 42 days using the proposed method and experts' opinion through the questionnaires and the fuzzy Delphi method, and about 4 days of improvement was achieved in the estimation of project completion time in comparison to the CPM. In other words, using the proposed method, scheduling was closer to reality and the effect of uncertainties on the results is greatly reduced.

Table 6

Validating the results of CPM, PERT and proposed method for calculating the duration of activities

\begin{tabular}{|c|c|c|c|c|c|c|c|c|}
\hline \multirow{2}{*}{ Activity number } & \multicolumn{3}{|c|}{ Estimated duration (days) } & \multirow{2}{*}{$\begin{array}{l}\text { Real du- } \\
\text { ration } \\
\text { (days) }\end{array}$} & \multicolumn{3}{|c|}{ Difference (days) } & \multirow{2}{*}{ : } \\
\hline & $\mathrm{CPM}$ & PERT & $\begin{array}{c}\text { Proposed } \\
\text { method }\end{array}$ & & $\mathrm{CPM}$ & PERT & $\begin{array}{c}\text { Proposed } \\
\text { method }\end{array}$ & \\
\hline 1 & 8.00 & 8.33 & 8.05 & 7.00 & 1.00 & 1.33 & 1.05 & $\checkmark$ \\
\hline 2 & 7.00 & 7.33 & 7.10 & 6.00 & 1.00 & 1.33 & 1.10 & $\checkmark$ \\
\hline 3 & 4.00 & 4.00 & 3.00 & 2.00 & 2.00 & 2.00 & 1.00 & $\checkmark$ \\
\hline 4 & 2.00 & 2.00 & 2.35 & 2.00 & 0.00 & 0.00 & 0.35 & $\checkmark$ \\
\hline 5 & 8.00 & 7.83 & 8.25 & 10.00 & -2.00 & -2.17 & -1.75 & \\
\hline 6 & 7.00 & 7.00 & 6.70 & 6.00 & 1.00 & 1.00 & 0.70 & $\checkmark$ \\
\hline 7 & 5.00 & 5.00 & 2.95 & 2.00 & 3.00 & 3.00 & 0.95 & $\checkmark$ \\
\hline 8 & 2.00 & 2.17 & 2.35 & 2.00 & 0.00 & 0.17 & 0.35 & $\checkmark$ \\
\hline 9 & 2.00 & 2.00 & 1.20 & 1.00 & 1.00 & 1.00 & 0.20 & $\checkmark$ \\
\hline 10 & 7.00 & 7.00 & 6.90 & 8.00 & -1.00 & -1.00 & -1.10 & $\checkmark$ \\
\hline 11 & 2.00 & 2.00 & 1.75 & 2.00 & 0.00 & 0.00 & -0.25 & $\checkmark$ \\
\hline \multicolumn{5}{|c|}{ Sum of absolute deviations } & 12.00 & 13.00 & 8.80 & -- \\
\hline
\end{tabular}

Also, Fig. 2 represents the project completion time calculated using various techniques as well as their error values.

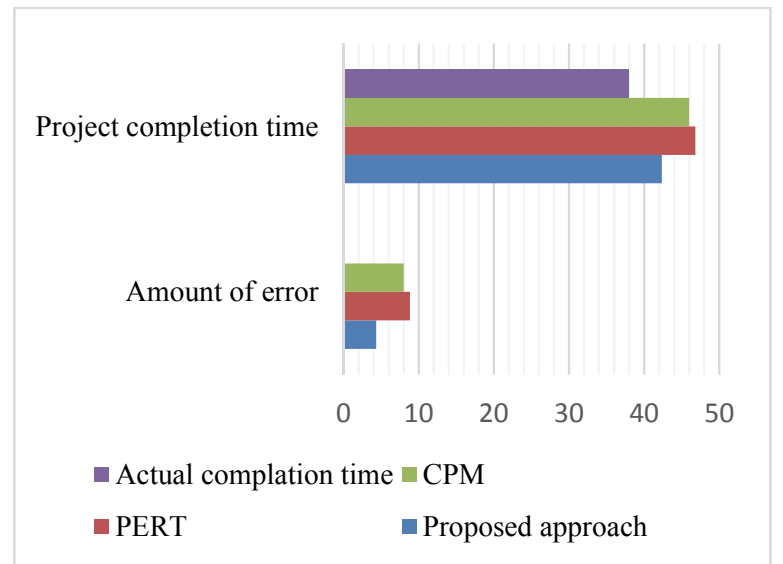

Fig. 2. Comparing the performance of methods for estimating durations

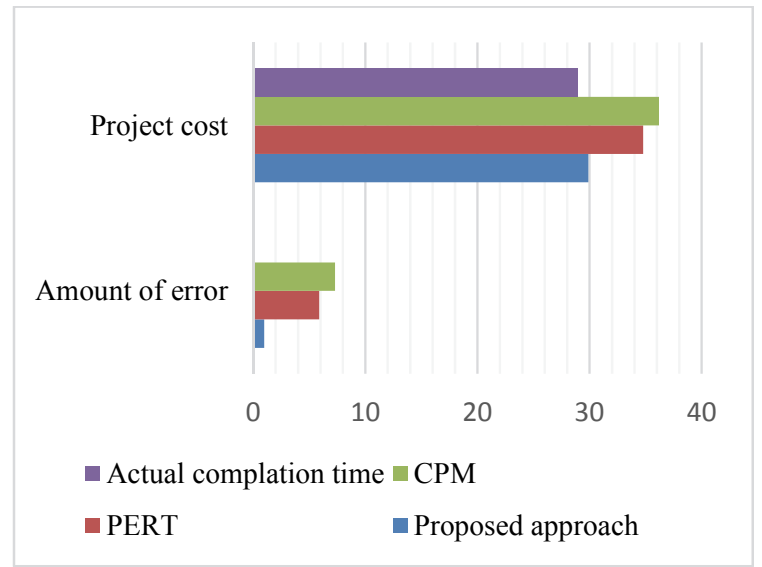

Fig. 3. Comparing the performance of methods for estimating costs

\subsection{Results of cost estimation}

According to the Table 7, the actual cost of project was 28.9 million monetary units. This value was 36.2 million monetary units using the CPM, and 34.78 million monetary units by the PERT. However, the implementation cost of the project was 29.88 million monetary units using the proposed method. 
According to the proposed method, the implementing cost of project close to the reality with a difference of about 0.98 million monetary units, and a relative improvement was obtained in the project cost estimation. Therefore, we can conclude that the estimation of project implementation cost was closer to the reality, and effect of uncertainties on results were greatly reduced.

Table 7

Validating the results of CPM, PERT and proposed method for calculating the cost of activities

\begin{tabular}{|c|c|c|c|c|c|c|c|c|}
\hline \multirow{2}{*}{ Activity number } & \multicolumn{3}{|c|}{$\begin{array}{c}\text { Estimated cost } \\
\text { (million monetary units) }\end{array}$} & \multirow{2}{*}{$\begin{array}{l}\text { Real cost } \\
(\mathrm{mmu})\end{array}$} & \multicolumn{3}{|c|}{$\begin{array}{c}\text { Difference } \\
\text { (million monetary units) }\end{array}$} & \multirow{2}{*}{ : } \\
\hline & CPM & PERT & $\begin{array}{c}\text { Proposed } \\
\text { method }\end{array}$ & & CPM & PERT & $\begin{array}{c}\text { Proposed } \\
\text { method }\end{array}$ & \\
\hline 1 & 2.50 & 3.00 & 1.94 & 2.00 & 0.50 & 1.00 & -0.06 & $\sqrt{ }$ \\
\hline 2 & 9.00 & 8.42 & 8.10 & 8.00 & 1.00 & 0.42 & 0.10 & $\checkmark$ \\
\hline 3 & 2.00 & 2.00 & 1.40 & 1.00 & 1.00 & 1.00 & 0.40 & $\checkmark$ \\
\hline 4 & 1.00 & 0.78 & 0.77 & 1.00 & 0.00 & -0.22 & -0.23 & $\checkmark$ \\
\hline 5 & 8.00 & 7.50 & 5.90 & 6.00 & 2.00 & 1.50 & -0.10 & \\
\hline 6 & 3.00 & 3.50 & 2.70 & 2.00 & 1.00 & 1.50 & 0.70 & $\checkmark$ \\
\hline 7 & 1.50 & 1.50 & 1.24 & 1.00 & 0.50 & 0.50 & 0.24 & $\checkmark$ \\
\hline 8 & 2.00 & 1.58 & 1.32 & 0.80 & 1.20 & 0.78 & 0.52 & $\checkmark$ \\
\hline 9 & 6.50 & 6.00 & 5.96 & 6.50 & 0.00 & -0.50 & -0.54 & $\checkmark$ \\
\hline 10 & 0.40 & 0.20 & 0.26 & 0.20 & 0.20 & 0.00 & 0.06 & $\checkmark$ \\
\hline 11 & 0.30 & 0.30 & 0.30 & 0.40 & -0.10 & -0.10 & -0.10 & $\checkmark$ \\
\hline $\begin{array}{l}\text { Sum of costs of criti- } \\
\text { cal activities }\end{array}$ & 28.20 & 27.28 & 23.98 & 22.90 & -- & -- & -- & -- \\
\hline Total cost & 36.20 & 34.78 & 29.88 & 28.90 & -- & -- & -- & -- \\
\hline $\begin{array}{c}\text { Sum of absolute de- } \\
\text { viations }\end{array}$ & -- & -- & -- & -- & 7.50 & 7.52 & 3.05 & -- \\
\hline
\end{tabular}

Fig. 3 also shows the implementing cost of the project estimated using various techniques as well as their error values.

\section{Conclusion}

As it was described, classical methods for estimating time and cost of the project such as the Critical Path Method (CPM) and the Project Evaluation and Review Technique (PERT) do not lead to satisfactory results due to the weaknesses in their performance and lack of efficiency in facing with uncertainties. The use of fuzzy theory and getting help from experienced experts for estimating time and cost planning are among the basic ways to deal with such problems. In this regard, the present paper provided a fuzzy-based methodology for estimating time and cost of project to reduce the impact of uncertainties on the obtained results. In this methodology, a survey was conducted on experts about the time and cost of activities and their opinions were obtained in the most optimistic, possible optimistic, possible pessimistic, and the most pessimistic states and expressed as fuzzy numbers. Finally, the estimation was done after averaging and defuzzifying. In order to understand how this framework was implemented and evaluate the performance of the proposed framework, a case study was carried out about the construction of a 5-story building in Tehran, Iran. According to the compared results, the proposed method significantly reduced the impact of uncertainties on obtained results compared to the CPM and PERT and then led to a relative improvement in the estimated time and cost of project completion. In summarily, the proposed framework has the following advantages:

- Ease of use and simplicity of calculations

- Expressing the time and cost of activities as linguistic variables

- Direct use of experts' mental inference, experience and opinions

- Considering the amount of credibility of experts 
Since the survey on experts and the type of fuzzy function have significant effects on the results, future studies are suggested using other fuzzy functions (except trapezoidal) to estimate the project time and cost and compare the obtained results with those of present study.

\section{References}

Adler, P. S., Mandelbaum, A., Nguyen, V., \& Schwerer, E. (1995). From project to process management: An empirically-based framework for analyzing product development time. Management science, 41(3), 458-484.

Anavi-Isakow, S., \& Golany, B. (2003). Managing multi-project environments through constant workin-process. International Journal of Project Management, 21(1), 9-18.

Azaron, A., Perkgoz, C., \& Sakawa, M. (2005). A genetic algorithm approach for the time-cost tradeoff in PERT networks. Applied mathematics and computation, 168(2), 1317-1339.

Bhosale, V., Shastri, S. S., \& Khandare, M. A. (2017). A Review of Genetic Algorithm used for optimizing scheduling of Resource Constraint construction projects.

Chanas, S., \& Kamburowski, J. (1981). The use of fuzzy variables in PERT. Fuzzy sets and systems, 5(1), 11-19.

Chanas, S., \& Zieliński, P. (2001). Critical path analysis in the network with fuzzy activity times. Fuzzy sets and systems, 122(2), 195-204.

Chen, C. T., \& Huang, S. F. (2007). Applying fuzzy method for measuring criticality in project network. Information sciences, 177(12), 2448-2458.

Chitra, K., \& Halder, P. (2017). Scheduling Project Crashing Time Using Linear Programming Approach: Case Study. International Journal of Research in Industrial Engineering, 6(4), 283-292.

Dolabi, H. R. Z., Afshar, A., \& Abbasnia, R. (2014). CPM/LOB scheduling method for project deadline constraint satisfaction. Automation in Construction, 48, 107-118.

Habibi, F., Barzinpour, F., \& Sadjadi, S. (2018). Resource-constrained project scheduling problem: review of past and recent developments. Journal of Project Management, 3(2), 55-88.

Kaufmann, A., \& Gupta, M. M. (2003). Introduction to fuzzy arithmetic: theory and applications. 1985. Von nostrand Reinhold Company, New York.

Mazlum, M., \& Güneri, A. F. (2015). CPM, PERT and Project Management with Fuzzy Logic Technique and Implementation on a Business. Procedia-Social and Behavioral Sciences, 210, 348-357.

Mon, D. L., Cheng, C. H., \& Lu, H. C. (1995). Application of fuzzy distributions on project management. Fuzzy sets and systems, 73(2), 227-234.

Shipley, M. F., de Korvin, A., \& Omer, K. (1997). BIFPET methodology versus PERT in project management: fuzzy probability instead of the beta distribution. Journal of Engineering and Technology management, 14(1), 49-65.

Zadeh, L. A. (2005). Toward a generalized theory of uncertainty (GTU) - an outline. Information sciences, 172(1-2), 1-40.

Zareei, S. (2018). Project scheduling for constructing biogas plant using critical path method. Renewable and Sustainable Energy Reviews, 81, 756-759.

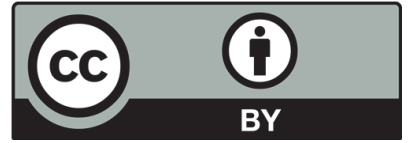

(C) 2018 by the authors; licensee Growing Science, Canada. This is an open access article distributed under the terms and conditions of the Creative Commons Attribution (CC-BY) license (http://creativecommons.org/licenses/by/4.0/). 